\title{
Studying the Effect of Process Controlling Agent on the Microstructure, Electrical and Thermal Conductivities of Copper /Graphene Composite Prepared by PM
}

\author{
A.T. Hamed ${ }^{1, *}$, E. S. Mosa ${ }^{2}$, A. A. Mahdy ${ }^{2}$, I. G. El-batanony ${ }^{3}$, O. Alkady ${ }^{4}$ \\ ${ }^{1} 15^{\text {th }}$ of May Higher Institute of Engineering, Cairo, Egypt. \\ ${ }^{2}$ Mining, Metallurgy and petroleum Engineering Department, Faculty of Engineering, AL-Azhar University, Cairo, Egypt \\ ${ }^{3}$ Mechanical Engineering Dept., Faculty of Engineering, Al-Azhar University, Cairo, Egypt \\ ${ }^{4}$ Manufacturing Technology Department, Central Metallurgical Research and Development Institute (CMRDI), Cairo, Egypt
}

*Corresponding author: E-mail: ashrafsattalaat@gmail.com, Tel: (+2) 01116764199

Received: 9 March 2021

Revised: 8 June 2021

Accepted for publication 27 June 2021

Published online: 30 June 2021

\begin{abstract}
Copper-graphene composite is prepared with $0.25,0.50,0.75,1.00,1.25$ and $1.50 \mathrm{wt} . \%$ graphene. Powder metallurgy technique is used for the preparation process. In which copper powder is mechanically milled with graphene nanosheets (GNSs) by 10: 1 ball to powder ratio, and $400 \mathrm{rpm}$ for $12 \mathrm{hr}$ milling time. The mixtures are compacted by a uniaxial press under $700 \mathrm{Mpa}$ pressure. The compacted samples are sintered under a controlled atmosphere at $950{ }^{\circ} \mathrm{C}$ for $1.5 \mathrm{hrs}$. A comparison between methanol \& hexane as a process control agent is established. The effect of both on the microstructure, electrical and thermal conductivities of the prepared $\mathrm{Cu} /$ graphene nanocomposites is studied. All results indicated that hexane samples have a more homogeneous microstructure with low porosity. For the two groups (Hexane and Methanol group samples), the density was decreased gradually by increasing the graphene percentage. The results indicated that both the electrical and thermal conductivities decrease by increasing graphene content. $1 \mathrm{wt}$. \% graphene sample has the most homogenous microstructure, while, $0.25 \mathrm{wt}$. \% graphene is the most one for the methanol group samples. Generally, all results indicated that hexane is the better PCA than methanol.
\end{abstract}

Keywords: Copper composites; Graphene; Mechanical alloying; Process control agent (PCA); Electrical conductivity.

\section{Introduction}

Copper alloys and composites have been broadly utilized as designing parts because of their great thermal and electrical properties and synthetic steadiness. In most cases, they suffer from poor mechanical properties, particularly under temperature load. For both electronic and mechanical applications $\mathrm{Cu}$ amalgams need decent physical and mechanical properties. The upgrade of their mechanical presentation is progressively required. The best system to accomplish unrivalled strength is the presentation of support stages in $\mathrm{Cu}$ composites and compounds to create $\mathrm{Cu}$ lattice composites [1]. $\mathrm{Cu}$ tragically has a high coefficient of thermal expansion (CTE) and low strength. So fabricating $\mathrm{Cu}$ composite supported with a low (CTE) material with high strength produces materials appropriate for many applications. Graphene,

has a significant properties as a nanofiller material because of its extraordinary electrical $105 * 104 \mathrm{~cm}^{2} / \mathrm{Vs}$, thermal $\left(5^{*} 103 \mathrm{~W} / \mathrm{mK}\right)$, and mechanical (1 TPa Young's modulus and $130 \mathrm{GPa}$ tensile strength) properties. It is a solitary layer of sp2-hybridized covalently reinforced carbon particles, masterminded in a two-dimensional, hexagonal cross-section see. Fig.1. Graphene surface can be effectively polished via airborne hydrocarbons, as presented to encompassing air and covering their wettability characteristic.

The innovative difficulties in assembling graphene built up MMCs are more normal than on account of polymer-lattice composites. This is because of the solid van der Waals forces between fragrant rings of graphene is difficult to scatter consistently into a metal framework as it will agglomerates to decrease its 
surface energy during the preparation process. Likewise, the interfacial holding is difficult because of the helpless affinity of graphene to metals. Specifically, copper $(\mathrm{Cu})$ doesn't wet graphene and covalent holding is absurd as no responses happen among $\mathrm{Cu}$ and graphene, which simply leaves feeble mechanical grip and van der Waals connections, the frequently wrinkled construction of graphene assumes a significant part in improving the mechanical interlocking between the graphene and $\mathrm{Cu}$, which prompts a superior burden move. A final challenge is that graphene can without much of a stretch become harmed during the brutal creation conditions (i.e. High temperature and high pressing factor) normally utilized to deliver MMCs, debilitating its inborn properties. Accordingly, a critical test in assembling graphene MMCs is their creation, which typically delivered by powder metallurgy courses.

$\mathrm{Cu}$ /graphene composites have some difficulties in the manufacturing process, such as the homogeneous scattering of graphene in the grid, the arrangement of a solid interfacial holding and the maintenance of the underlying soundness of graphene. Powder metallurgy is an adaptable interaction for assembling composites with graphene because of its straight forwardness, flexibility, and close shape capacity [1]. The measure fundamentally includes blending graphene with crude metallic powders to set up the composite powders followed by their combination into a mass shape. This last advance contains the compaction of the composite cycle and additionally densification cycles, for example, sintering, squeezing, and additionally rolling [2]. The crude metallic powders utilized will in general be unadulterated $\mathrm{Cu}$ powders or $\mathrm{Cu}$ compounds comprising of atomized $\mathrm{Cu}$ blended with alloying powders [3]. Mechanical blending can deliver composites with great microstructures and homogeneous dispersion of graphene in the $\mathrm{Cu}$ grid. The composite powders can be set up by basic blending strategies including mechanical or attractive sonication and vortex technique. High-energy ball processing $(\mathrm{BM})$ or mechanical alloying (MA) have been likewise employed.[4] Mechanical alloying is the strong state preparing of powder materials which is frequently used to create combinations and composites that are difficult to get from regular dissolving and projecting techniques [1-3]. The processing energy can be controlled by fluctuating the ball to powder proportion, the processing time speed, also the processing environment. A process control agent (PCA), like stearic acid or ethanol, is added to forestall extreme staying and agglomerations of $\mathrm{Cu}$ powders during the manufacturing processing [4]. Natural solvents (for example ethanol) should be dissipated to get dry composite powders before compaction and consolidation [5].

A couple of methods to clean the graphene surface is thermal toughening, UV-O3 openness, dissolvable, and cleaning. Thermal toughening has the advantage utilized to eliminate poly-methyl. Thermal tempering at $550{ }^{\circ} \mathrm{C}$ eliminates air-borne hydrocarbons from the graphene surface. The utilization of UV/O3 brings about a similar impact of eliminating the hydrocarbons from the graphene, diminishing the water contact point. This procedure can't be utilized for a long time since UV radiation may be harmful for the graphene surface causing abandons that can likewise bring down the contact point of the graphene with the metal matrix. In some methodology, single-layer graphene was suradjusted with initiated carbon and thermal tempering at $210{ }^{\circ} \mathrm{C}$. This work aims at studying the effect of methanol or hexane as a PCA on the microstructure \& physical properties of $\mathrm{Cu}$-graphene nano composites for electrical \& electronic applications.

\section{Experimental work}

In this work, powder metallurgy method was used for manufacturing of $\mathrm{Cu}$-Graphene (GNSs) nanocomposites. Copper and graphene microstructure is shown in Fig.1(a, b) in which, $\mathrm{Cu}$ with $75 \mu \mathrm{m}$ and $99.90 \%$ purity supplied from (International Co. for Scientific \& Medical) is reinforced with 0.25 , $0.50,0.75,1.00,1.25$ and 1.50 wt. \% graphene nanosheets that has $50 \mathrm{~nm}$ particle size and 99.95 purity supplied from (Fiber Max Composites company, Greece). High energy ball mill is used in mixing $\mathrm{Cu}$ with nano graphene by $400 \mathrm{rpm}$ mixer/mill with a ballto-powder ratio of 10:1 \& $12 \mathrm{hr}$ milling time
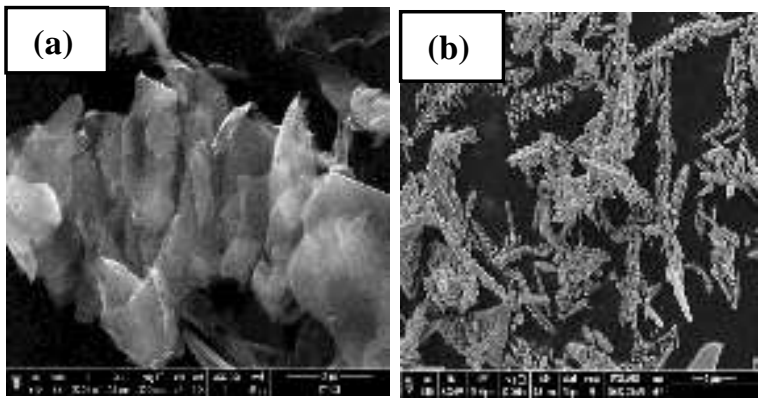

Fig. 1 SEM images of: (a) Graphene (b),Copper.

The mechanical alloying technique is processed using two types of process controlling agent (PCA) which are hexane \& methanol. So, $10 \%$ from each one is added separately to the milled mixture to study their effects on the microstructure of the produced $\mathrm{Cu}$ graphene nanocomposites. Also, paraffin wax as a 
lubricant material is added by $0.5 \mathrm{wt} \%$ during the compaction process to decrease the friction with the die. The mixing process was established using a stainlesssteel vessel then, the mixed powders were dried in an oven for one hour at about $100{ }^{\circ} \mathrm{C}$ to melt the paraffine wax and to let it mix well with $\mathrm{Cu}-\mathrm{GNSs}$ mixture. Then, the mixture was compressed in a cylinder die has $8 \mathrm{~mm}$ diameter and $12 \mathrm{~mm}$ height made from $\mathrm{Cr}-\mathrm{Mo}$ alloy steel (DINW302). The hydraulic uni-axial pressing was done under compaction pressure of $700 \mathrm{MPa}$. The sintering process was achieved in a vacuum furnace at $950{ }^{\circ} \mathrm{C}$ for $1.5 \mathrm{hr}$ by a heating rate of $3{ }^{\circ} \mathrm{C} / \mathrm{min}$ up to $250^{\circ} \mathrm{C}$ where the temperature was holded for $15 \mathrm{~min}$. in a dewaxing step. Then the heating rate was increased to $950{ }^{\circ} \mathrm{C}$ by $4^{\circ} \mathrm{C} / \mathrm{min}$. and holding for $90 \mathrm{~min}$ then the furnace was cooled. For microstructure examination, the specimens were grinding with $220,400,600,800$, 1000, 1200, 2000, and 3000 grit SiC paper and polished with 6-micron diamond paste. Microstructure was studied using a digital camera type cannon PC1049 fitted with ZIESS lenses, also by field emission scanning electron microscope (FESEM; QUANTAFEG250). The actual density of the prepared samples was estimated according to Archimedes rule, using water as a floating liquid. The sintered specimens were weighed in air and in distilled water and the actual density $\left(\rho_{\text {act. }}\right)$ were determined according to the full owing equation (1): -

$$
\boldsymbol{\rho}_{\text {act. }}=\frac{\mathbf{w}_{\mathbf{a}}}{\mathbf{w}_{\mathrm{a}}-\mathbf{W}_{\mathbf{w}}} \ldots \ldots \ldots \ldots \ldots \ldots \ldots \ldots \ldots \text { Eq. (1) }
$$

Where Wa and $\mathrm{Ww}$ are the weight of the sample in air and water, respectively. The theoretical density $\left(\rho_{\text {th. }}\right)$ for the investigated composite was determined according to the following equation (2):-

$\boldsymbol{\rho}_{\text {th. }}=\left(\mathbf{V}_{\mathbf{M}} * \boldsymbol{\rho}_{\mathbf{M}}\right)+\left(\mathbf{V}_{\mathbf{R}} * \boldsymbol{\rho}_{\mathbf{R}}\right) \ldots \ldots \ldots$ Eq. (2)

Theoretical Density Where VM and RM are the volume fraction and density of the matrix while VR and $\rho R$ are those for the reinforcement sample. [7-8]

Relative Density $=\boldsymbol{\rho}_{\text {act. }} / \boldsymbol{\rho}_{\text {th. }} \ldots \ldots \ldots \ldots$ Eq. (3)

The electrical conductivity, resistivity and IACS \% were estimated for the sintered samples. The test was established using (Material Tester for Metal, PCECOM20). Then thermal conductivity is calculated using Wiedemann and Franz equation, which is a relation between electrical and thermal conductivity [7]. Wiedmann-Franz relation as shown in the following equation (4):-

$\mathrm{K} / \boldsymbol{\sigma}=\mathbf{L T}$
Where, $\mathrm{K}$ is the thermal conductivity in $\mathrm{W} / \mathrm{m} . \mathrm{k}, \boldsymbol{\sigma}$ is the electrical conductivity $\mathrm{s} / \mathrm{m}, \mathrm{L}$ is Lorenz constant which equals $2.44 * 10-8 \mathrm{w} . \Omega / \mathrm{k} 2$ value and $\mathrm{T}$ is the absolute temperature in $\mathrm{oK}$.

\section{Results and discussion}

Two groups of samples are prepared; one of them is the $\mathrm{Cu}$-Graphene nanosheets (GNSs) composite with hexane as a PCA and the other with methanol. This section illustrates and discusses the microstructure, electrical and thermal conductivities of the sintered composites.

\subsection{Microstructure Examination}

Fig. 2 shows the microstructure of $\mathrm{Cu}-\mathrm{Graphene}$ nanosheets (GNSs) composites, (a, b, c and d) represent the prepared samples by methanol as a process controlling agent, while (e, $\mathrm{f}, \mathrm{g}$ and $\mathrm{h}$ ) are those for the hexane ones. Generally, by comparing the two groups, one can notice that samples prepared using hexane have a good microstructure, good homogeneity between Graphene nanosheets (GNSs) and $\mathrm{Cu}$ matrix. Etch microstructure area divided to three regions watch are white grey, grey and black areas. The white grey area represents the $\mathrm{Cu}$ matrix, the grey area represents the Graphene nanosheets (GNSs) and the black ones are belonging to the pores.

Generally, GNSs did not wet copper as the surface energy between them is high, so no good dispersion of the GNSs in the copper matrix takes place [13]. Addition of PCA and good milling parameters (milling time, ball to powder ratio and number of rotations rpm) are controllable to adjust the composite preparation. It is clear that in case of hexane samples, no pores are observed and Graphene nanosheets (GNSs) are good distributed all over the $\mathrm{Cu}$ matrix with very small agglomerations. While the methanol group samples have some porosity. This may be attributed to the hexane nature in which hexane is a long chain organic solvent, has six carbon atoms with no oxygen, so it is an inert organic solvent with low evaporation temperature.

Hexane dissolves all the organic contaminants on the graphene nanosheets surface, which facilitate the dispersion of it in the $\mathrm{Cu}$ matrix with a relative wettability, and no agglomerations are observed. While methanol contains oxygen in its structure, which can react with any contaminations on the graphene surface, so the graphene surface may be not cleaned totally by methane, consequently some aggregations takes place. Another observation from the microstructure is the $1 \mathrm{wt}$. $\% \mathrm{Cu}$-graphene sample for the hexane group has the most homogeneous microstructure and lowest pore percent, while 0.25 wt.\% graphene sample for the methanol group is the best one. 

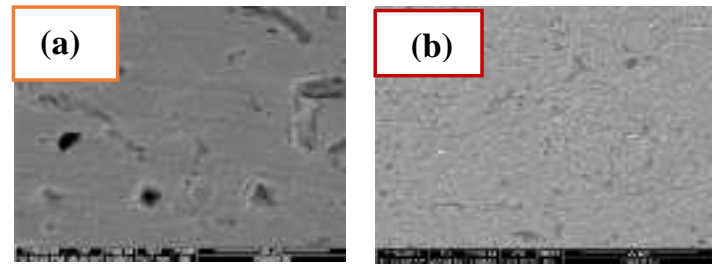

(Methanol)0.25wt.\%G

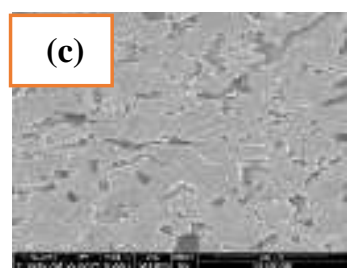

(Methanol)0.50wt.\% Gr

(Methanol) $1.0 \mathrm{wt} . \% \mathrm{Gr}$

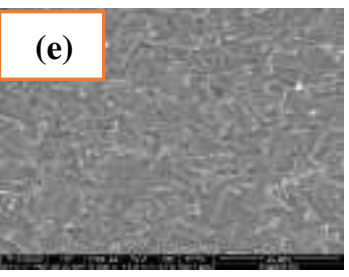

(Hexane) $0.25 w t . \% \mathrm{Gr}$

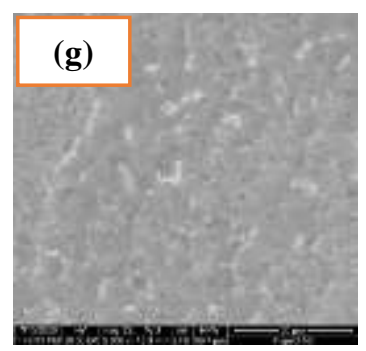

(Hexane) 1.00 wt. \% Gr
(Methanol)1.50wt. \% Gr
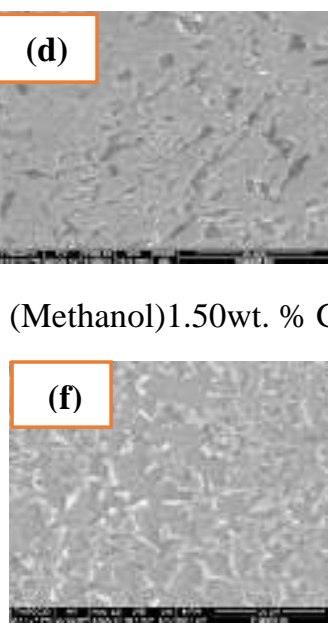

(Hexane) $0.50 \mathrm{wt} . \% \mathrm{Gr}$

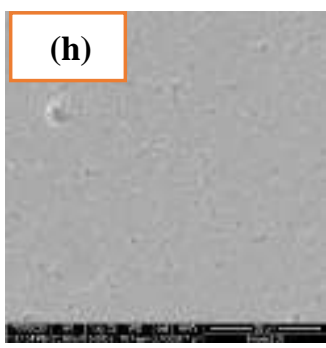

(Hexane) 1.50 wt. \% Gr

Fig. 2 SEM of sintered Cu-GNSs composite (a, b, c and d) methanol group (e, f , g and h) hexane group.

Fig. 3 (a, b) shows the EDX of Cu 1 wt. \% graphene nanosheets (GNSs) sample with methanol and hexane respectively. It is clear that the samples have a good homogenous dispersion with low $\mathrm{Gr}$ agglomerations due to the good milling process between $\mathrm{Cu}$ and Graphene nanosheets (GNSs), also using hexane as a PCA in as shown in Fig. 3 b, while, the reverse for (a) that used methanol (PCA).

Table 1 \& Fig. 4 show the effect of Graphene nanosheets (GNSs) on the relative density of $\mathrm{Cu}-\mathrm{NSs}$ composites prepared with methanol and hexane as a PCA. The Figure shows two phenomena the first is the decreasing density value by increasing the graphene percent for both groups. This is may be attributed to the

lower density value of graphene $\left(2.2 \mathrm{~g} / \mathrm{cm}^{3}\right)$ than that of $\mathrm{Cu}\left(8.96 \mathrm{~g} / \mathrm{cm}^{3}\right)$.
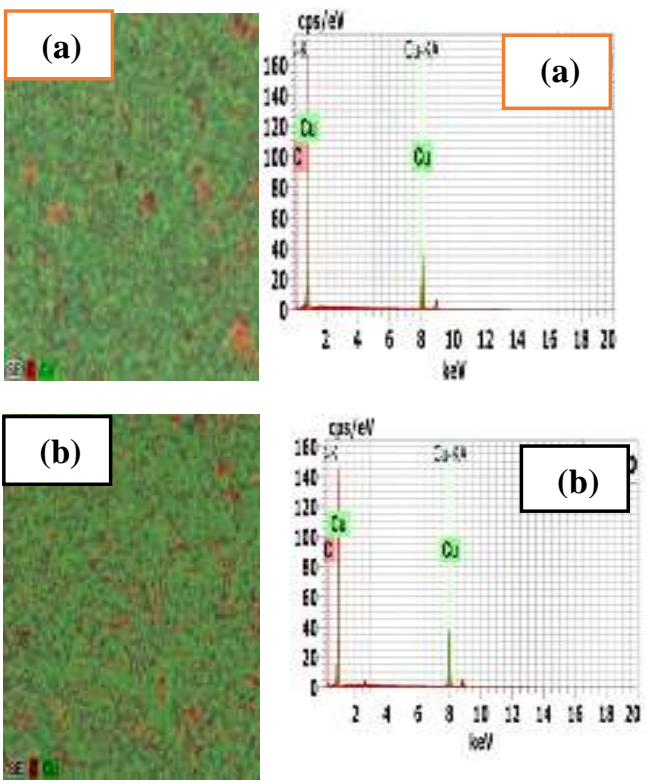

Fig. 3 EDX of sintered (a) $\mathrm{Cu} / 1$ wt. \% GNSs (M),(b) $\mathrm{Cu} / 1$ wt. \% GNSs (H).

Table 1. Relative density measured value.

\begin{tabular}{|l|l|l|}
\hline Sample GNSs \% & $\begin{array}{l}\text { Hexane group } \\
\%\end{array}$ & $\begin{array}{l}\text { Methanol } \\
\text { group \% }\end{array}$ \\
\hline $\mathrm{Cu}$ pure & 92.39 & 90.88 \\
\hline $\mathrm{Cu}+0.25$ & 89.96 & 85.53 \\
\hline $\mathrm{Cu}+0.50$ & 88.35 & 81.23 \\
\hline $\mathrm{Cu}+0.75$ & 87.88 & 78.21 \\
\hline $\mathrm{Cu}+1.00$ & 86.35 & 76.32 \\
\hline $\mathrm{Cu}+1.25$ & 84.69 & 75.83 \\
\hline $\mathrm{Cu}+1.50$ & 83.20 & 72.19 \\
\hline
\end{tabular}

The second phenomena are the increasing density value of hexane group samples than those of methanol ones. This is due to the hexane nature in which it facilitates the separation of graphene nanosheets layers from each other, consequently, good dispersion of it in the $\mathrm{Cu}$ matrix without aggregations takes place [8]. 


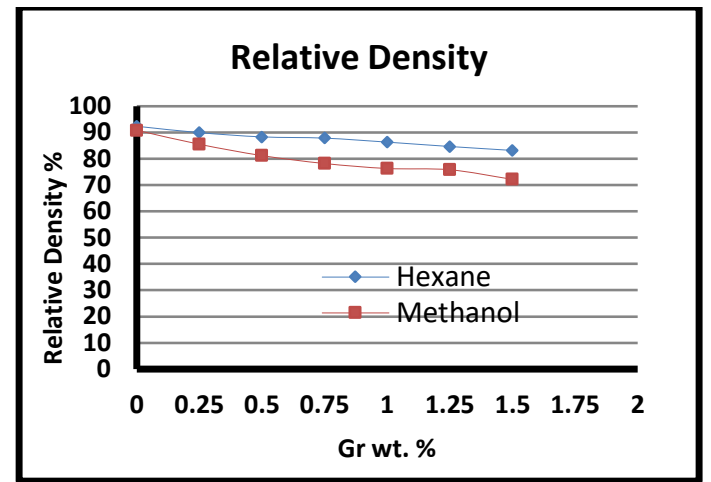

Fig. 4 Relative Density versus graphene wt. \% for $\mathrm{Cu}$ GNSs (hexane), Cu-GNSs (methanol) composites.

\subsection{Electrical Conductivity}

Tables 2, 3 \& Fig. 5. show the effect of graphene percent on the electrical conductivity value of $\mathrm{Cu}$ GNSs composites. There are two phenomena; the first is the decreasing of conductivity values by increasing the graphene percent. Although graphene is a conductive material, yet the conductivity of $\mathrm{Cu}$ / Graphene nanosheets (GNSs) composites decreases by increasing graphene percent. This may be due to the non-wettability problem between the metallic copper and the graphene nanosheets that has a ceramic nature. In which high surface energy between them has occurred, so. Some agglomerations take place and pores have formed that cause the decrease in the electrical conductivity values as the pores restrict the electron's motion that responsible for the conductance [7]. The second phenomenon is the increase in the conductivity values of the hexane group samples than those of the methanol ones. This may be attributed to the nature of hexane which is a nonpolar solvent that has the ability for dissolving any organic contaminations on the graphene surface and prevent cold welding between particles during the milling process. While methanol is a polar solvent that has a co bond that can be cleavage during the milling process and release oxygen that may react with the milled particles. Also, it cannot dissolve the contaminations on the GNSs surface completely, so some aggregations take place leading to the pore formation. The formed pores have zero conductivity so, the total conductance is decreased [12].

The $\mathrm{Cu}$ /graphene electrical conductivity is usually expressed in \% IACS which is used to estimate the electrical conductivity for metals and alloys relative to the standard annealed copper metal whose conductivity is $58 \mathrm{MS} / \mathrm{m}$ at $20{ }^{\circ} \mathrm{C}$.[9] Owing to the excellent electrical conductivity of graphene, it has been used as a filler for the enhancement of the electrical conductivity of $\mathrm{Cu}$. As a matter of fact, an improvement as high as $20-30 \%$ was recorded for electrodeposited particulate composite films [10]. So, from the literature, one can conclude that the enhancement of the electrical conductivity in $\mathrm{Cu}$ /graphene composites is sometimes quite modest or even negative compared with the unreinforced alloys, the improvement enhancements depending on the graphene percent, and the processing route conditions

Table 2. Electrical conductivity for Methanol group.

\begin{tabular}{|c|c|c|c|}
\hline $\begin{array}{l}\text { Sample GNSs \% } \\
\text { Methanol Group }\end{array}$ & $\mathbf{M s} / \mathbf{m}$ & $\mathbf{\Omega} \mathbf{~ m}^{\mathbf{2}} / \mathbf{m}$ & IACS \\
\hline $\mathrm{Cu}$ pure & 42.5 & 0.02350 & 73.4 \\
\hline $\mathrm{Cu}+0.25$ & 31.0 & 0.03222 & 53.5 \\
\hline $\mathrm{Cu}+0.50$ & 23.79 & 0.04204 & 41.0 \\
\hline $\mathrm{Cu}+0.75$ & 21.01 & 0.04758 & 36.2 \\
\hline $\mathrm{Cu}+1.00$ & 20.73 & 0.04824 & 35.70 \\
\hline $\mathrm{Cu}+1.25$ & 15.86 & 0.06303 & 27.35 \\
\hline $\mathrm{Cu}+1.50$ & 10.25 & 0.09757 & 17.67 \\
\hline
\end{tabular}

Table 3. Electrical conductivity for Hexane group.

\begin{tabular}{|c|c|c|c|}
\hline $\begin{array}{l}\text { Sample GNSs \% } \\
\text { Hexane Group }\end{array}$ & $\mathbf{M s} / \mathbf{m}$ & $\mathbf{\Omega} \mathbf{~ m}^{\mathbf{2}} / \mathbf{m}$ & IACS \\
\hline $\mathrm{Cu}$ pure & 42.5 & 0.02350 & 73.4 \\
\hline $\mathrm{Cu}+0.25$ & 36.7 & 0.02721 & 63.4 \\
\hline $\mathrm{Cu}+0.50$ & 25.68 & 0.03893 & 44.3 \\
\hline $\mathrm{Cu}+0.75$ & 25.23 & 0.03963 & 43.5 \\
\hline $\mathrm{Cu}+1.00$ & 24.91 & 0.04014 & 43.0 \\
\hline $\mathrm{Cu}+1.25$ & 23.39 & 0.04276 & 40.3 \\
\hline $\mathrm{Cu}+1.50$ & 16.94 & 0.05902 & 29.21 \\
\hline
\end{tabular}

\section{Electrical conductivity}

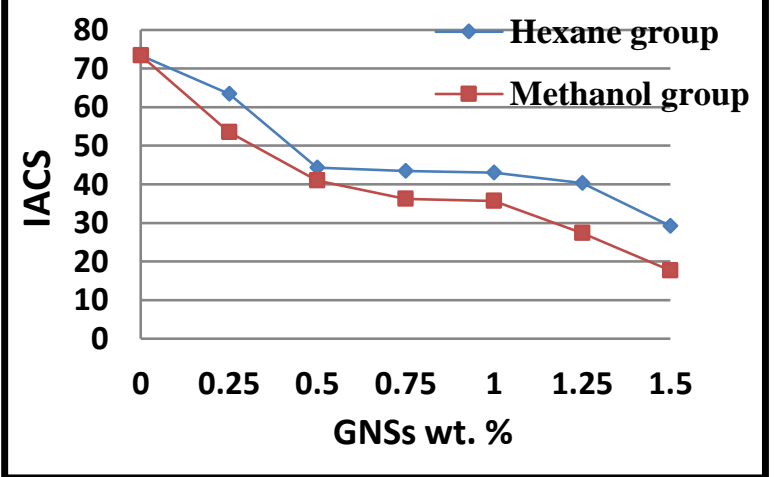

Fig. 5 Electrical conductivity for $\mathrm{Cu}-\mathrm{GNSs}$ (Hexane \& Methanol. 


\subsection{Thermal conductivity}

Tables 4,5 Fig. 6. shows the relationship between the graphene percent and the thermal conductivity of the prepared samples. It is clear that the thermal conductivity decreases gradually by increasing the graphene percent. This is may be attributed to the pores formed during the sintering process due to the agglomerations that take place as a result of the increase of surface energy between $\mathrm{Cu}$ and graphene.

Table 4. Thermal conductivity of Methanol group.

\begin{tabular}{|c|l|}
\hline $\begin{array}{l}\text { Sample GNSs \% } \\
\text { Methanol Group }\end{array}$ & $(\mathbf{K}) \mathbf{W} / \mathbf{m . k}$ \\
\hline $\mathrm{Cu}$ pure & 305.086 \\
\hline $\mathrm{Cu}+0.25$ & 222.539 \\
\hline $\mathrm{Cu}+0.50$ & 170.777 \\
\hline $\mathrm{Cu}+0.75$ & 150.820 \\
\hline $\mathrm{Cu}+1.00$ & 148.810 \\
\hline $\mathrm{Cu}+1.25$ & 113.851 \\
\hline $\mathrm{Cu}+1.50$ & 73.580 \\
\hline
\end{tabular}

Table 5. Thermal conductivity Hexane group

\begin{tabular}{|c|c|}
\hline $\begin{array}{l}\text { Sample GNSs \% } \\
\text { Hexane Group }\end{array}$ & $(\mathbf{K}) \mathbf{W} / \mathbf{m . k}$ \\
\hline $\mathrm{Cu}$ pure & 305.086 \\
\hline $\mathrm{Cu}+0.25$ & 263.450 \\
\hline $\mathrm{Cu}+0.50$ & 184.344 \\
\hline $\mathrm{Cu}+0.75$ & 181.114 \\
\hline $\mathrm{Cu}+1.00$ & 178.816 \\
\hline $\mathrm{Cu}+1.25$ & 167.905 \\
\hline $\mathrm{Cu}+1.50$ & 121.603 \\
\hline
\end{tabular}

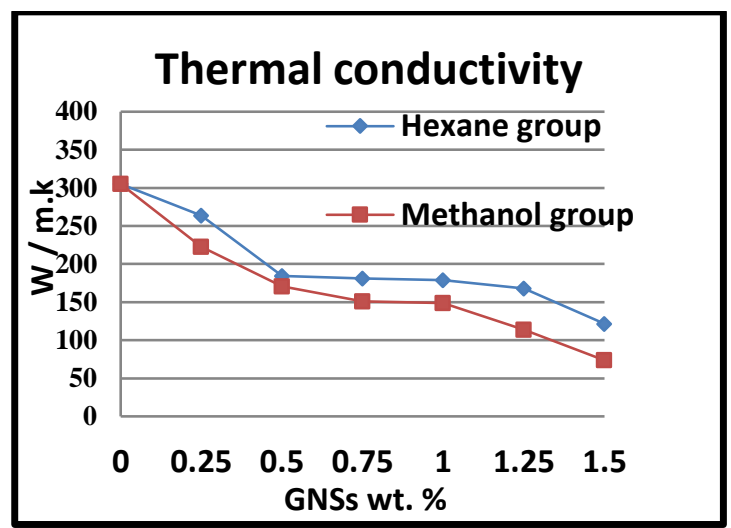

Fig. 6 Thermal conductivity for $\mathrm{Cu}-\mathrm{GNSs}$ (Hexane \& Methanol).

The increase in the aggregation of graphene and the formation of pores that have zero conductivity is the main reason for this phenomenon. Also, the hexane group has a higher thermal conductivity value than those of the methanol ones. This is also due to the nature of hexane which causes the separation of graphene layers in a good manner and facilitates the motion of the heat in the matrix by conduction and convection due to the low pores. While for methanol group samples, some pores are formed that retards the heat transformation in the formed composites.[11] Although both the electrical \& thermal conductivities are decreased by graphene additions, yet is it is still in the working area of $\mathrm{Cu}$ composite applications.

\section{Conclusions}

From the obtained results, one can conclude the followings:

1. $\mathrm{Cu}$ - graphene nanosheets can be prepared by the powder metallurgy (PM) technique.

2. Hexane is most suitable as a Process Control agent (PCA) than methanol.

3. Hexane group samples have a good microstructure than the methanol samples.

4. The density values of the hexane group are higher than those of the methanol ones.

5. Both the electrical and thermal conductivities are decreased gradually by increasing Graphene nanosheets (GNSs) percent, but they are still in the working area of $\mathrm{Cu}$ composites.

6. To improve the microstructure, electrical and thermal conductivities of $\mathrm{Cu}-\mathrm{GNS}$ s composites the non-wettability problem must be solved and hexane is preferably used as a PCA.

\section{References}

[1] S. C. Tjong. Recent progress in the development and properties of novel metal matrix nanocomposites reinforced with carbon nanotubes and graphene nanosheets. Mater Sci Eng R. 74,( 2013), P. 281350.

[2] S. R. Bakshi. Carbon nanotube reinforced metal matrix composites - a review. Int Mater Rev 55(2010) , P. 41-64.

[3] C. Suryanarayana, Mechanical alloying and milling, Prog Mater Sci 46(2010) 1-184

[4] H. Yue, L. Yao. Effect of ball-milling and graphene contents on the mechanical properties and fracture mechanisms of graphene nanosheets reinforced copper matrix composites. J Alloys Comp. 691, (2017) 755-762.

[5] P.H. Manrique, Copper/graphene composites: a review, J Mater Sci, 54(2019) 12236-12289.

[6] D. Parobek, H. Liu. Wettability of graphene, $2 D$ Mater. 2 (2015), 032001. 
[7] A. Fathy a, Omyma El-Kady. Thermal expansion and thermal conductivity characteristics of $\mathrm{Cu}-$ $\mathrm{Al}_{2} \mathrm{O}_{3}$, nanocomposites. Materials \& Design, 46 (2013) 355-359.

[8] H. Saad. Effect of Carbon Nano Tubes (CNT) and Silicon Carbide (SiC) on Mechanical Properties of Pure Aluminium Manufactured by Powder Metallurgy. Journal of Materials Research and Technology, 9 (2019) 1948-1954.

[9] Y .Cui, L Wang, Li B, Cao G, Fei W. Effect of ballmilling on the defeat of few-layer graphene and properties of copper matrix composites. Acta Metall Sin Eng Let t. 27, (2014) 937-943.

[10] K. Jagannadham. Volume fraction of graphene platelets in copper-graphene composites. Metall Mater Trans A, 44 (2013) 552-559.

[11] Khobragade, N., Kumar, B., Bera, S., \& Roy, D. Studies on graphene reinforced $\mathrm{Cu}$ base composites prepared by two step thermal processing method. Materials Today: Proceedings, 4(8). (2017) 8045-8051

[12] M.M. Mohammed, A. Fathy, O. .El-Kady. Effect of $\mathrm{Al}_{2} \mathrm{O}_{3}$ addition on hardness and wear behavior of $\mathrm{Cu}-\mathrm{Al}_{2} \mathrm{O}_{3}$ electro-less coated $\mathrm{Ag}$ nanocomposite Journal of Materials Research and Technology, 9, (2020) 5024-5033.

[13] H. M. Yehia, A. Abu-Oqail, Maher, A. Elmaghraby, O. El-kady. Microstructure, hardness, and tribology properties of the $\left(\mathrm{Cu} / \mathrm{MoS}_{2}\right)$ /graphene nanocomposite via the electroless deposition and powder metallurgy technique. J of Composite Mater. 54, (2020) 34353446. 